\title{
Are Pinctada radiata (Leach, I8 I4) and Pinctada fucata (Gould, 1850) (Bivalvia Pteriidae) only synonyms or really different species? The case of some Mediterranean populations
}

\author{
Danilo Scuderi", Paolo Balistreri' \& Alfio Germanà ${ }^{3}$ \\ II.I.S.S. “E. Majorana”, via L. Capuana 36, 95048 Scordia, Italy; e-mail: danscu@tin.it \\ ${ }^{2}$ ARPA Sicilia Trapani, Viale della Provincia, Casa Santa, Erice, 91016 Trapani, Italy; e-mail: requin.blanc@hotmail.it \\ ${ }^{3}$ Via A. De Pretis 30, 95039, Trecastagni, Catania, Italy; e-mail: alfiogermana@virgilio.it \\ ${ }^{*}$ Corresponding author
}

ABSTRACT

The earliest reported alien species that entered the Mediterranean after only nine years from the inauguration of the Suez Canal was "Meleagrina" sp., which was subsequently identified as the Gulf pearl-oyster, Pinctada radiata (Leach, 1814) (Bivalvia Pteriidae). Thereafter, an increasing series of records of this species followed. In fact, nowadays it can be considered a well-established species throughout the Mediterranean basin. Since the Red Sea isthmus was considered to be the only natural way of migration, nobody has ever doubted about the name to be assigned to the species, $P$. radiata, since this was the only Pinctada Röding, 1798 cited in literature for the Mediterranean Sea. Taxonomy of Pinctada is complicated since it lacks precise constant morphological characteristics to distinguish one species from the others. Thus, distribution and specimens location are particularly important since different species mostly live in different geographical areas. Some researchers also used a molecular phylogenetic approach, but the results were discordant. This taxonomic conundrum was reexamined this time applying morphological taxonomy. Increasing vessel traffic and records of vast amounts of Pinctada specimens with morphologically different shells led us to formulate the hypothesis that a separate Pinctada population of different geographical provenance could be present. Specimens were grouped according to the site of collection in the Mediterranean basin. Results from these morphological studies confirmed that, according to us, there were two distinct species, $P$. radiata and $P$. fucata (Gould, 1850). Morphological comments and interpretations on the taxonomical status of both species together with autoecological notes and a literature review of the molecular phylogenetic studies conducted will be here presented.

KEY WORDS

Pinctada imbricata complex; Pteriidae; pearl oyster; Recent; Mediterranean Sea.

Received 10.07.2018; accepted 12.09.2018; published online 20.12.2019

Proceedings of the 4th International Congress on Biodiversity "Man, Natural Habitats and Euro-Mediterranean Biodiversity", November 17th-19th, 2017 - Malta

\section{INTRODUCTION}

Just only nine years after the inauguration of the Suez Canal, Monterosato (1878) reported for the first time "Meleagrina" sp. for the Mediterranean Egypt (Alexandria), where it was so abundant that it was sold in the local fish markets.

He admitted not to know whether it was a local 
still unknown species or the earliest reported lessepsian species, as it was. Subsequently the species was doubtfully described as new as Meleagrina savignyi Monterosato, 1884 (Bivalvia Pteriidae), later identified as Pinctada radiata (Leach, 1814) (Parenzan, 1961; Bombace, 1967; Paccagnella, 1967; Spada, 1969).

Since modern times, this latter name has never been questioned and nobody has ever doubted if under this name more than one species could be hidden.

Taxonomy of the species of Pinctada Röding, 1798 is complicated because of the extreme variability of species in this genus and seems far to be clearly defined. In fact $P$. radiata has been considered as conspecific with $P$. fucata (Gould, 1850) (see Hynd, 1955) and, later on, as mere synonyms (Ranson, 1961) ("alternate representation" in WoRMS).

Some important factors, like wide geographical distribution and anthropic contribution to hybridization, are reported by Temkin (2010) as affecting the extreme polymorphism of species.
As a consequence, a molecular phylogenetic approach was used by some researchers but the results were still discordant: see for instances Temkin (2010) and Cunha et al. (2011).

For this reasons, the former Author stated the lacking to date of precise constant morphological characters, in particular to discriminate species of the so called " $P$. radiata" group, for which three different clines have been distinguished and taxonomically related by him to geographical sub-species: P. imbricata imbricata Röding, 1798 in the western Atlantic areas, $P$. imbricata radiata in the eastern Indian Ocean and the Red Sea areas and P. imbricata fucata in the IndoPacific areas.

As the modes of introduction of this pearl oyster in the Mediterranean Sea, more than one have been described in the literature: intentional introduction by mariculture; shipping, which is considered to be the most likely introduction vector of non-indigenous species (Zibrowius, 1992) and even by migrant trips of the sea turtle Caretta caretta (Linnaeus, 1758) (Oliverio et al., 1992).

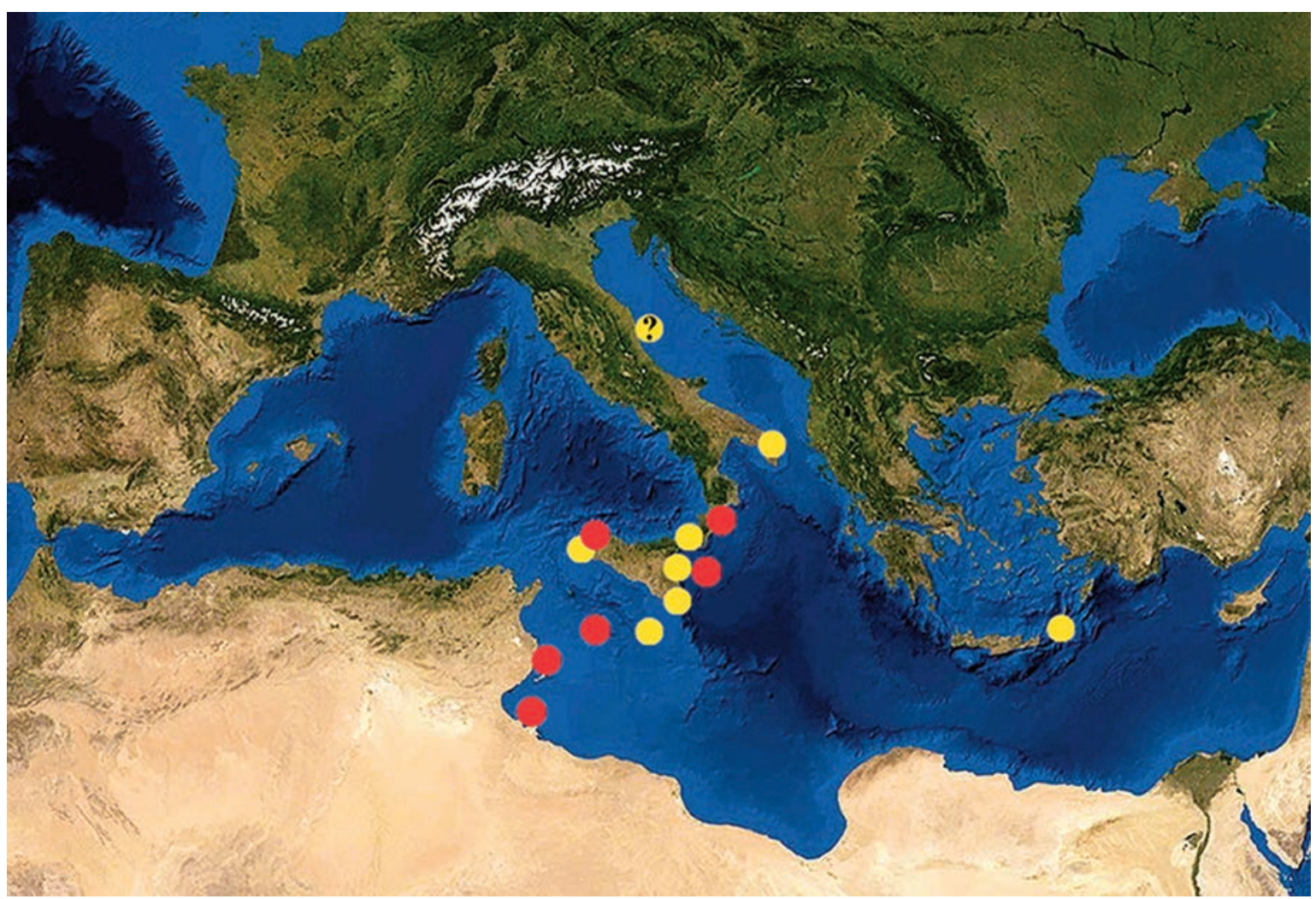

Figure 1. Map of the sampled area: red circles refer to $P$. radiata findings, yellow circles to $P$. fucata findings. The "?" refers to doubtful provenance. 
Nowadays throughout the Southern Central and Eastern Mediterranean $P$. radiata can be considered a well-established species.

But the genetic diversity of populations of this species in the basin seems to exhibit low values, as reported by Barbieri et al. (2015).

In this last years in Sicily consistent materials of another morphologically different population of Pinctada were found along the Eastern coast (Villari \& Scuderi, 2017), from Messina to Siracusa, in different environmental conditions compared to the quantitatively less important finding of $P$. $r a$ diata.

As suggested by these latter Authors, the model of settlement and spreading of this populations in these localities follows the model of a newly entered alien species. In fact specimens appeared in massive quantities in these localities where no other specimen of Pinctada since XIX century was previously recorded, with the exception of only one single shell in the harbor of Catania (Di Geronimo, 1971).

The Northern and the most Southern part of the island was reached only in a second time, with less consistent populations, being the harbor of Catania identified as the location of first settlement, probably after human mediated transportation.

Currently the population of Eastern Sicily benefits a good state of health, since large number of specimens were found just in winter 2018.

In the present paper, the taxonomic conundrum previously reported was re-examined applying morphological taxonomy to the above mentioned materials of both the morphs of Pinctada.

The study of this materials allowed us to discriminate two different groups on account of shell morphology, anatomy of the external soft parts and environment.

The first could be grouped under the so far known taxon $P$. radiata, while, according to us, the second represents a different species which here we call $P$. fucata, after comparisons with Indo-Pacific material. So, the real question is more general and trespass the Mediterranean limits: are these two taxa only synonyms of a single very variable species or they could indeed be considered a different species? A resume of the literature data on biomolecular studies conducted to solve doubts on the identity of species of this complex are here furnished together with our new personal observations on the morphology of both the shell and the soft body parts.

Comments and personal interpretations of the taxonomical status of both these morphs are here reported as an attempt to give our contribution to their complicated taxonomy.

\section{MATERIAL AND METHODS}

A total number of 1284 living specimens and shells of both the morphs were examined from many different Mediterranean localities, from central N-African coasts to the more Eastern places of the basin (Fig. 1), and grouped according to the collection site in the Mediterranean, studying the variation inside populations.

More accurate data are furnished in Table 2 for each morph debated in the following lines.

The most abundant population is that from the sandy coast of Catania (E-Sicily), where numerous alien species of animals and algae are constantly found during these last years.

Living specimens were found on a removable containment boom, which was installed on June 15 2018 and removed on September 18 of the same year. Some Indo-Pacific specimens of P. fucata, from Maldives Islands, were studied for morphological comparisons.

Specimens were measured and the shell morphology was studied: nomenclature of characters follows Wada \& Temkin (2008).

We utilized as valid characters: the general outline, the sculpture and the prevalent colour of valves, the hinge structure and the shape of ligament and ligament area.

Living specimens were housed in aquarium and dissected: specimens of the two morphs were comparable in size (Figs. 39, 41).

Anatomical studies concerned the presence and shape of the anal funnel and colour of soft parts.

Table 1 lists the main characters utilized to distinguish $P$. radiata and $P$. fucata used in this study.

ACRONYMS AND ABBREVIATIONS. AGC: Alfio Germanà Collection, Catania, Italy; AVC: Alberto Villari Collection, Messina, Italy; DSC: Danilo Scuderi Collection, Catania, Italy; PBC: Paolo Balistreri Collection, Favignana, Trapani, Italy; PMC: Pasquale Micali Collection, Fano, Italy; WRC: Walter Renda Collection, Amantea, 
Cosenza, Italy; sh.: empty shell/s; sp.: living collected specimen/s.

\section{RESULTS}

\section{Systematics}

Classis BIVALVIA Linnaeus, 1758

Subclassis PTERIOMORPHIA Beurlen, 1944

Ordo OSTREIDA Férussac, 1822

Superfamilia PTERIOIDEA Gray, 1847 (1820)

Familia PTERIIDAE Gray, 1847 (1820)

\section{Pinctada Röding, 1798}

TYPE SPECIES: Pinctada margaritifera (Linnaeus, 1758). Here follows the description of the main diagnostic characters observed for each of the two taxa treated in the present paper.

Pinctada radiata (Leach, 1814)

(Figs. 2-7, 17-19, 23, 35, 36, 39, 40)

EXAMINED MATERIAL. A total of $84 \mathrm{sh}$ and $48 \mathrm{sp}$ from different localities from Italy and Tunis (see Table 2 for details).

DESCRIPTION. Shell almost rounded in outline, variable in thickness and inequilateral (Fig. 27), high up to $75 \mathrm{~mm}$, constituted by almost flat valves, the left more convex than the right one.

Outer face reddish with darker radial rows, sculptured by numerous concentric growth lamellae which bear, on the lower $1 / 2$ or $1 / 3$ of the valve, a copious number of pointed and narrow processes arranged in two orders: one larger alternated to one or two smaller (Fig. 27).

In the posterior margin of both the valves the rows are closer. The smooth inner surface is divided in a marginal less wide non-nacreous layer, which recalls the outer surface in colour, separated by a darker more or less wide band from the nacre one, which bears a wide adductor muscle scar and a series of small pallial muscle scars.

The right valve shows a not very marked rounded byssal ridge. The hinge bears a well-defined and duplicated posterior tooth and a not very well defined but thick anterior tooth with two not deep sockets.
The left valve shows a very marked rounded byssal ridge and bears a straight and clearly duplicated anterior tooth; posterior tooth not marked.

Straight hinge line, which become almost deeply curved near the umbo. Seen from inner side, the umbo is prominent in the left valve, almost invisible in the right one.

Anatomy of soft parts: digestive gland, kidney, gonad and ctenidium deep orange (Fig. 35); foot whitish with numerous black spots; ctenidium and margin of mantle orange with white stains and black radial bands corresponding to the marginal tips; anal funnel (Fig. 36) speare-shaped and graysh. Byssus green with almost thick filaments (Fig. 40).

Distribution AND Biology. Quite common in Eastern basin, from Israel, Crete, Grece to Tunisia, Eastern and Western Sicily and S-Apulia. Tyrrhenian records should be confirmed with live-collected specimens.

Calcareous to lava hard substrata, with dense algal turf, at low depths $(-0.5 / 8 \mathrm{~m})$.

Pinctada fucata (Gould, 1850)

(Figs. 8-26, 20-22, 24, 37, 38, 41-50)

EXAMINED MATERIAL. A total of $761 \mathrm{sh}$ and 392 sp from different localities from Italy, Greece and Malta (see Table 2 for details). Maldives: Ari Atoll, Kuda Rah, $96 \mathrm{Km} \mathrm{S}$ of Male, beached, $5 \mathrm{sh}$ (DSC).

DESCRIPTION. Shell almost transverse-oval in outline, fragile and highly inequilateral (Fig. 26), high up to $45 \mathrm{~mm}$, with a flat right valve and a left quite convex one. Colour very variable, from almost white specimens with darker stains to yellow, red, but the most common is green, within its wide range of variations, from paler to very dark, with whitish radial rows.

It is sculptured by concentric almost smooth growth lamellae, which bear, on the lower $1 / 3$ or $1 / 4$ of the valve, a low number of blunt and large processes arranged in two orders of 10-12 alternated rows of bigger and smaller processes (Fig. 26).

In the posterior margin of both the valves the rows bear bigger processes: those of the 2 nd or 3 rd row could form very long and large scales which stand up over all the others (Figs. 12, 13). 


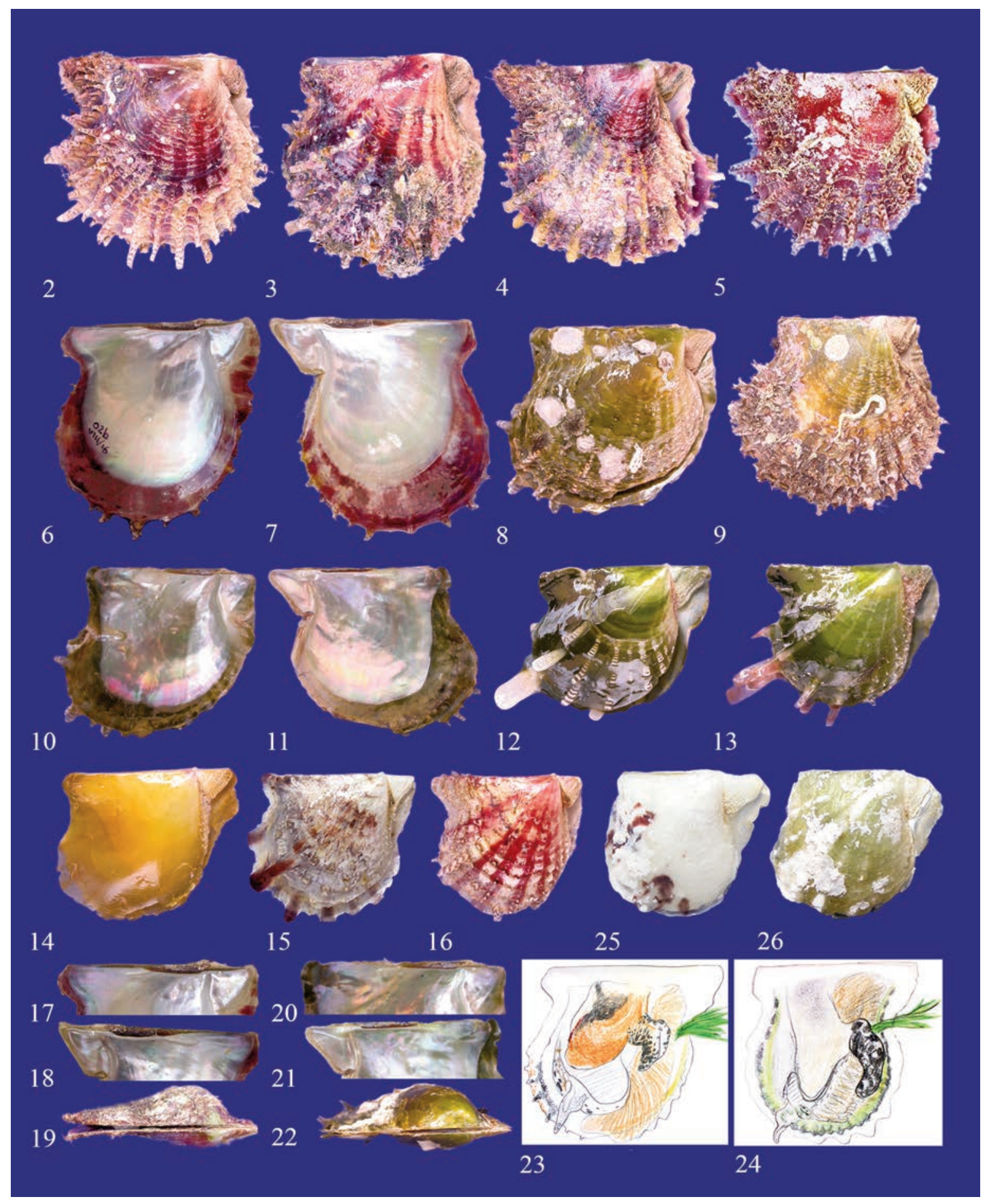

Figures 2-7, 17-19, 23. Pinctada radiata. Figs. 2-7: shells in external and internal view, all from Catania. Fig. 2: h: 59 mm. Fig. 3: h: 49 mm. Fig. 4: h: 42 mm. Fig. 5: h: 32 mm. Figs. 6, 7: h: 53 mm. Fig. 23, same data of the specimen in figure 4, drawing of the internal soft parts. Figs. 17-19, same data of the specimen in figures. 6, 7, detail of the hinge of the left (Fig. 17) and right (Fig. 18) valves and view from umbo (Fig. 19). Figures 8-16, 20-22, 24. Pinctada fucata. Figs. 8-16: shells in external and internal view, all from Catania. Figs. 8, 10-11: h: 46 mm. Fig. 9: h: 75 mm, corresponding to a possible hybrid specimen. Fig. 12: h: 20 mm. Fig. 13: h: 18 mm. Fig. 14: h: 31 mm. Fig. 15: h: 23 mm. Fig. 16: h: 26 mm. Figs. 20-22, same data of the specimen in figures 10, 11, detail of the hinge of the left (Fig. 20) and right (Fig. 21) valves and view from umbo (Fig. 22). Fig. 24: same data of the specimen in figure 41, drawing of the internal soft parts. Figs. 25, 26: Maldives Is., Ari atoll, h: $19 \mathrm{~mm}$ and h: $10 \mathrm{~mm}$, respectively. 


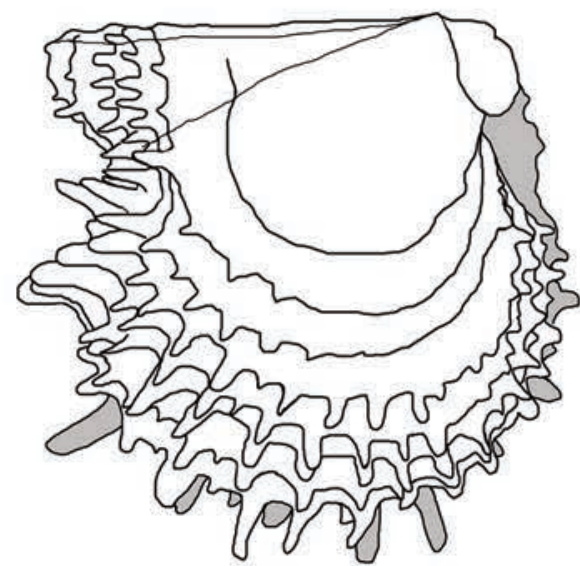

27

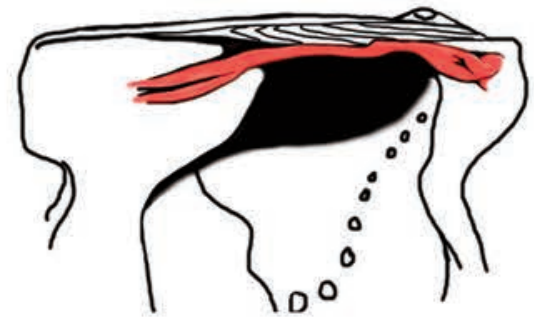

29

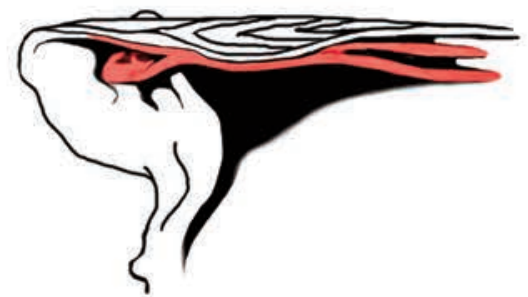

30

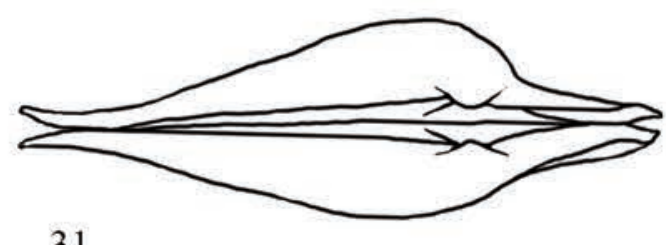

31

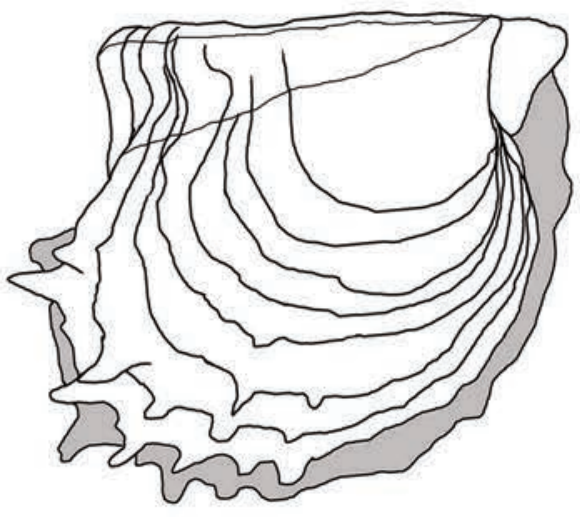

28

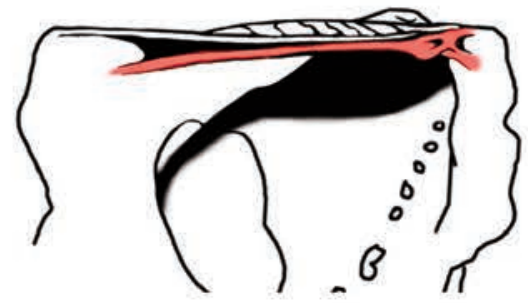

32

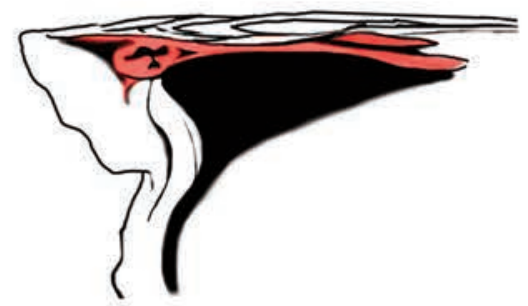

33

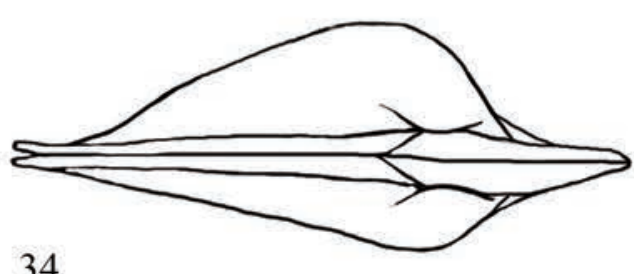

34

Figures 27, 28. Sketches of the shell outline respectively of Pinctada radiata and $P$. fucata (in gray margins of the lower valve). Figures 29-34. Sketches of the hinge in the left and right valve (in red details of the teeth) and shell outline seen from umbo of $P$. radiata (Figs. 29-31) and P. fucata (Figs. 32-34). 


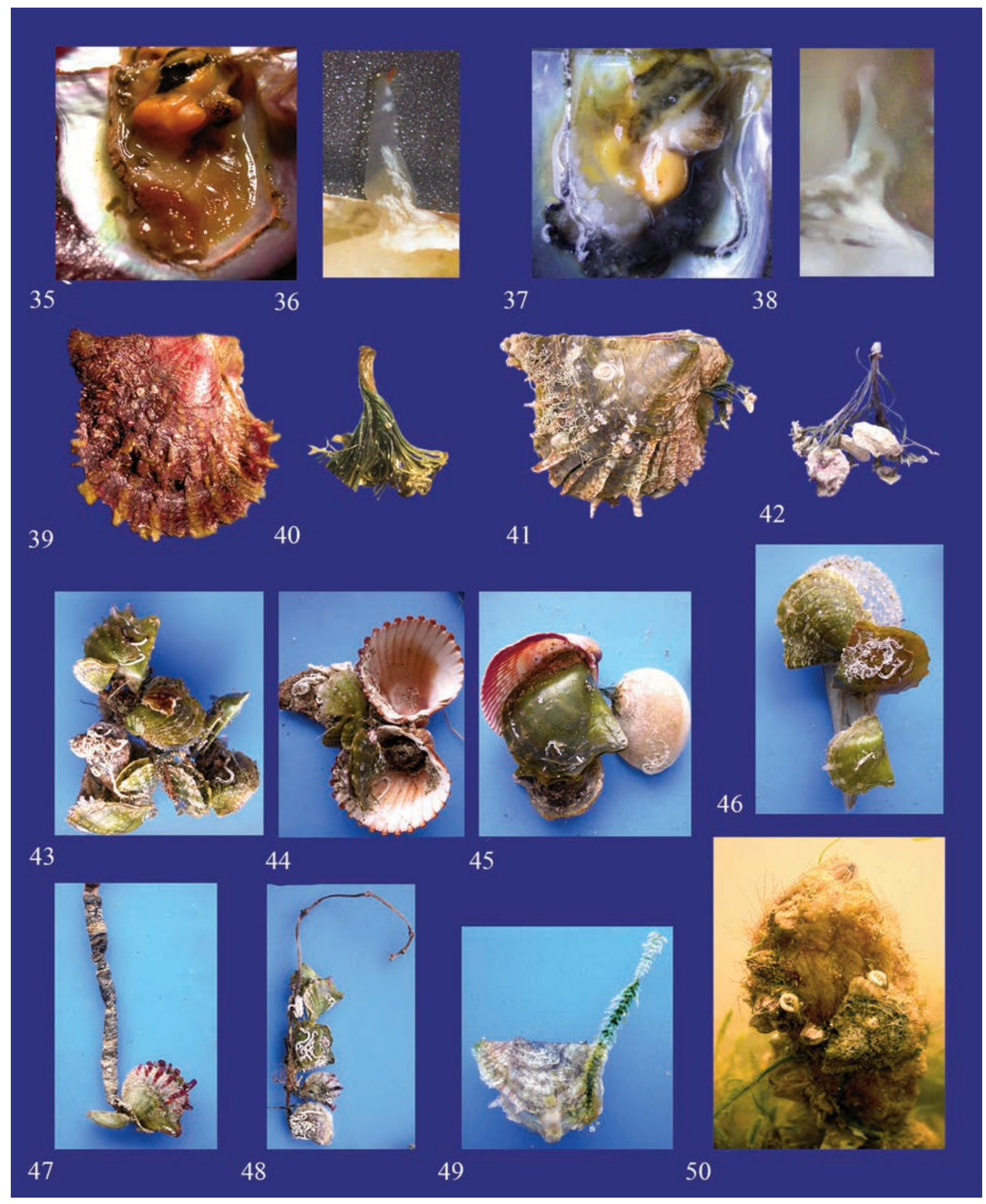

Figures 35, 36, 39, 40: Pinctada radiata. Fig. 35, photograph of the internal soft parts of the specimen in figure 39, h: 42 mm. Fig. 36, detail of the anal funnel. Fig. 40, byssus, same data of figure 35. Figures 37, 38, 41-50: Pinctada fucata. Fig. 37, photograph of the internal soft parts of the specimen in fig. 41, h: $40 \mathrm{~mm}$. Fig. 38, detail of the anal funnel. Fig. 42, byssus, same data of fig. 37. Figs. 43-50, living specimens attached to various substrata from Catania "Playa". Fig. 43, group of specimens attached each other. Fig. 44, specimens on valves of Acanthocardia tuberculata. Fig. 45: specimens on a valve of Fulvia fragilis and the shell of Neverita josephinae. Fig. 46: specimens on the shell of a small Pinna nobilis. Fig. 47: a specimen on the tube of Sabella spallanzanii. Fig. 48: specimens on a rhizome of Cymodocea nodosa. Fig. 49: a specimen on Caulerpa taxifolia var. distichophylla. Fig. 50, a specimen on an ascidian of the genus Microcosmus. 
The right valve shows a not very marked rounded byssal ridge.

The hinge bears a well-defined and duplicated posterior tooth and a not very well defined but thick anterior tooth with two often marked sockets.

The left valve shows a very marked rounded byssal ridge and bears straight and not duplicated anterior tooth; posteriorly an almost deep socket with two not market teeth is present.

Straight hinge line, which do not or only slightly become curved near the umbo. Seen from inner side, the umbo is prominent in the left valve, almost invisible in the right one.

Anatomy of soft parts: digestive gland, kidney and gonad pale orange to green, ctenidium greenish with white stains (Fig. 37); foot whitish with numerous black spots; margin of mantle deep green to pale orange, with white stains and black radial bands corresponding to the marginal tips, anal funnel graysh and speare-shaped (Fig. 38). Byssus green with almost thick filaments (Fig. 42).

Distribution and Biology. Sporadically reported in Eastern basin, in these last few years it is very abundant in Eastern Sicily and quite common in other Southern regions in Italy. The Adriatic record is reported fide the statements of the mariculture operators in Faro lake, Messina and should be confirmed. Sandy bottoms near estuarine areas, attached with byssus each other (Fig. 43) or on other shell, like mussels, Cardiidae (Fig. 44), Pinnidae (Fig. 46) and dead gastropods (Fig. 45), on ascidians (Fig. 50), on Annelid tubes (Fig. 47), to the stolons of the sea-grass Cymodocea nodosa (Ucria) Ascherson, 1870 (Fig. 48) or the algae Caulerpa taxifolia var. distichophylla (Sonder) Verlaque, Huisman et Procaccini in Jongma et al., 2013 (Fig. 49), but on plastic objects too, in low $(-1 / 8 \mathrm{~m})$ depths.

\section{DISCUSSION}

After a critical evaluation of the morphological characters observed in very abundant amount of specimens of the two different forms of Pinctada, despite a high variability in both and the genetic studies of mainly Eastern Mediterranean specimens (Barbieri et al., 2015), we concluded that two different species are involved

The first, attributable to $P$. radiata, on account of a bigger shell in full grown specimens, rounded in outline (Fig. 25), almost entirely red-brownish with darker radial strips, sculpture of dense and pointed process, organized in numerous rows, soft parts mainly orange (see Table 1).

The second is here named P. fucata, on account of comparisons with Indo-Pacific materials (Figs. $23,24)$, and is characterized by a smaller shell in full grown specimens, oval in outline (Fig. 26), almost greenish in colour ( $75-80 \%$ of the specimens observed) with paler radial strips, sculpture essential, tending to vanish (valves often almost smooth), process sparse, blunt and wider, organized in low number of rows, soft parts mainly greenish. The former species, seen from umbo, is quite flattened (Fig. 31), while the latter appears markedly convex.

Besides the morphological differences above mentioned, $P$. fucata differs in habitat preferences. While $P$. radiata is present, nowadays with dense populations in Southern regions of East and Central Mediterranean, on hard substrata with algal covering (Cystoseira spp.), P. fucata was instead found near river's estuary on other shells, but the most abundant material is represented by vegetal residuals of the river cane Phragmites australis (Cav.) Trin. ex Steud., accumulated by winter storms. Less commonly it was found on the ascidians of the genus Microcosmus Heller, 1877 (Ascidiacea Pyuridae).

Considering the complicated taxonomy and the high polymorphism of the species of Pinctada, all these morphological differences are, according to us, enough to consider the two different morphs here studied as different species. We therefore refer to the conclusions chapter the full reasons of our personal interpretation of the taxonomical problem concerning these two taxa.

Moreover, in E-Sicily P. fucata was sporadically collected or never recorded before, in the same locality where thousands of specimens have been found in very recent times.

This population shows preferences for more brackish waters and sandy bottoms, where is more likely arrived with human mediated transportation, as its population dynamics seem to suggest.

The current status of the above reported populations of $P$. fucata in E-Sicily seems to attest their progressive expansion, after a first period of acclimation in the more suitable geographical zones where they arrived. 


\begin{tabular}{|l|l|l|}
\hline \multicolumn{1}{|c|}{ Characters } & \multicolumn{1}{|c|}{ P. radiata } & \multicolumn{1}{c|}{ P. fucata } \\
\hline Shell outline & rounded & ovate \\
\hline Dimensions (height of the valve) & up to $75 \mathrm{~mm}$ & up to $45 \mathrm{~mm}$ \\
\hline Shell colour & red-brownish with darker vertical strips & greenish with paler vertical strips \\
\hline Anterior tooth of the left valve & duplicated & Not duplicated \\
\hline Hinge line & Curved near umbo & Straight \\
\hline Ligament area & Narrow & Wide \\
\hline Sculpture & numerous rows of dense and pointed & low number of rows of sparse, blunt \\
processes & and wider processes \\
\hline Soft parts colour & Mainly orange & Mainly greenish \\
\hline Environment & Hard substrates & Sandy bottoms near estuarine areas \\
\hline & &
\end{tabular}

Table 1. Comparison of morphological characters in P. radiata and P. fucata.

Specimens collected on a removable containment boom allowed us to evaluate the growth rate of the species: being the net completely clean at its first installation, after four months, among fouling, four specimens were found.

The medium grown rate of this species in the ESicily is $5.75 \mathrm{~mm}$ per month, which leaves us to believe that its expansion process in the Mediterranean Sea is very fast and facilitated by human activities.

\section{CONCLUSIONS}

According to differences in morphological characters of the shell and soft parts the two populations of Sicilian Pinctada are here considered different.

One, which we call $P$. radiata, has ever been recorded in scattered localities along the Sicilian rocky shores.

The second species, previously officially never recorded, appeared here only during the last 5-6 years, showing a population dynamic typical of an alien species.

But, if all the specimens constituting the large population reported as Meleagrina sp. by Monterosato (1878) from Alexandria belong to the same species figured in Appolloni et al. (2018), this species was the earliest lessepsian species spreading in the Mediterranean.

The disagreement of the present conclusions with previous molecular studies (Barbieri et al., 2015) according to us is attributable to the low number of specimens tested in these latter.

Probably previous records of $P$. radiata could be related to $P$. fucata too, like that of Crocetta et al. (2009), who found "hundreds specimens" along the Calabrian shores, among which some at list were $P$. fucata (specimens figured in Crocetta et al., 2009 at figures $2 \mathrm{O}, \mathrm{Q}$ ).

This latter species is present in Aegean Sea, as could be argued by pictures furnished by Manousis 


\begin{tabular}{|c|c|c|c|c|c|}
\hline Species & Locality and notes & coll. & sp & sh & Tot \\
\hline \multirow[t]{15}{*}{ P. fucata } & Italy, Catania, Playa, beached, 2014-2018 & DSC & 382 & 736 & \\
\hline & Italy, Catania, S. Giovanni Li Cuti, rocky bottom, $-2 / 8 \mathrm{~m}$, summer 2015-18 & DSC & 4 & 4 & \\
\hline & Italy, Catania, Cannizzaro, rocky bottom, -2/8m, summer 2016 & DSC & & 2 & \\
\hline & Italy, Messina, Faro lake, among mussels from Rimini (Adriatic), as stated by farm workers & AVC & 3 & & \\
\hline & Italy, Messina, Contrada Paradiso, Posidonia beds $-7 \mathrm{~m}$ & AVC & 3 & 12 & \\
\hline & Italy, Siracusa, Agnone, beached, III/2018 & DSC & 2 & 4 & \\
\hline & Italy, Siracusa, Porto grande, mouth of the Anapo river, 2017 & DSC & 2 & 3 & \\
\hline & Italy, Siracusa, Calabernardo, 1995-2015 & DSC & & 3 & \\
\hline & Italy, Siracusa, Terrauzza, 1998 & DSC & & 1 & \\
\hline & Italy, Trapani, Favignana, Cala Rotonda, -2m, 2017 & PBC & 1 & 2 & \\
\hline & Italy, Trapani, Ronciglio, beached, 2016 & PBC & & 5 & \\
\hline & Greece, Is. Karpathos, $-35 \mathrm{~m}$ & PMC-AGC & & 2 & \\
\hline & Cyprus N-E, $-12 m$ & AGC & 2 & & \\
\hline & Malta: Ghar id-Dud, beached & DSC & & 1 & \\
\hline & & & 397 & 775 & 1172 \\
\hline \multirow[t]{10}{*}{$P$. radiata } & Italy, Catania, S. Giovanni Li Cuti, rocky bottom, -2/8m, summer 2013-2018 & DSC & 15 & 36 & \\
\hline & Italy, Catania, Cannizzaro, -2/8m, summer 2017-2018 & AGC & 11 & & \\
\hline & Italy, Agrigento, Lampedusa, rocky bottom, $-2 / 6 \mathrm{~m}, 1989-2002$ & DSC & & 14 & \\
\hline & Italy, Agrigento, Linosa, rocky bottom, -2/6m, 1995 & DSC & 1 & 1 & \\
\hline & Italy, Lecce, Torre Guaceto, rocky bottom, 2010 & DSC & & 2 & \\
\hline & Italy, Reggio Calabria, Saline Joniche Harbour, on aquacolture nets, november 2008 & WRC & & 8 & \\
\hline & Tunisia, Djerba, El-Kantra, rocky bottom, -2/6m, april 2007 & AGC & 9 & 15 & \\
\hline & Tunisia, Kerkennah Is., rocky bottom, $-2 / 6 \mathrm{~m}$, summer 2014 & AGC & 12 & 8 & \\
\hline & & & 36 & 76 & 112 \\
\hline & & & & Total & 1284 \\
\hline
\end{tabular}

Table 2. Materials of $P$. radiata and $P$. fucata utilized in the present study.

\& Galinou-Mitsoudi (2013: fig. 4B), and is in rapid spreading in the Mediterranean, with large populations in certain localities, as could be argued by the growth rate of the species here attested.

Different species of Pinctada in the world seem to live in different geographical districts, but genetic differences between species seem not very high and molecular studies appeared controversial.

Moreover in geographical zones where the distribution areas overlap, morphological intermediates appear, adding confusions both to morphological and genetic studies.

Among the large amount of materials studied, we have found few intermediates between $P$. radiata and P. fucata as well (Fig. 9). So, how can we interpret these intermediates?

On the one hand, intermediates could represent morphs resulting by mating of different morphs of one only quite polymorphic species, which often live in different geographical areas.
But populations constituted by these morphologically different specimens tend to remain quite constantly uniform with respect to those of other geographic regions.

So, another interpretation is that they represent different species, which could hybridize themselves when populations overlap their distributional areas.

So, these intermediates represent hybrid specimens between two species.

Among bivalve molluscs, Mytylidae comprise examples of the same problem.

Genetic studies attested the existence of three different european species of Mytylus: M. galloprovincialis in the Mediterranean Sea and adjacent areas, M. edulis in North-Western coasts of Europe, and $M$. trossulus along Scandinavian coasts (Koehn, 1991).

Intermediates between these species occur along overlapping ridges of geographical distribution areas (Gardner et al., 1993; Gosling et al., 2008). 
Mytylidae is a family of bivalves phylogenetically similar to Pteriidae.

According to us, the case of the Mediterranean Pinctada hybrids is similar to that of the Mytylus species. Moreover, populations of different species, from different geographical areas hybridize themselves.

\section{ACKNOWLEDGEMENTS}

We are grateful to Bruno Amati (Roma, Italy), for interesting comments and for literature data furnished. Pasquale Micali (Fano, Italy), Walter Renda (Amantea, Italy) and Alberto Villari (Messina, Italy) are thanked for their helpful comments and loan of materials. The supervisors, Emanuele and Giuliano D'Arrigo, and the lifeguard team of the beach resort "Cocoa Beach" of Catania, Italy (Salvo Costanzo, Mirko Campo, Carmelo Pulvirenti and Carlo Esterini) are thanked for stimulating one of the Author (DS) to pick among the removable containment boom.

\section{REFERENCES}

Appolloni M., Smriglio C., Amati B., Lugliè L., Nofroni I., Tringali L.P., Mariottini P. \& Oliverio M., 2018. Catalogue of the primary types of marine molluscan taxa described by Tommaso Allery Di Maria, Marquis of Monterosato, deposited in the Museo Civico di Zoologia, Roma. Zootaxa, 4477: 1-138. https://doi.org/10.11646/zootaxa.4477.1.1

Barbieri M., Deidun A., Maltagliati F. \& Castelli A., 2015. A contribution to the phylogeography of Pinctada imbricata imbricata radiata (Leach, 1814) (Bivalvia: Pteriidae) from the Eastern Mediterranean Sea by means of the mitochondrial COI marker. Italian Journal of Zoology, 1-8. http://dx.doi.org/10.1080/ 11250003.2015.1106012

Bombace G., 1967. Sul rinvenimento di alcuni esemplari di Pinctada radiata (Leach) nelle acque del Canale di Sicilia (Mollusca, Bivalvia). Natura, 58: 298-304.

Crocetta F., Renda W. \& Vazzana A., 2009. Alien Mollusca along the Calabrian shores of the Messina Strait area and a review of their distribution in the Italian seas. Bollettino Malacologico, 45: 15-30.

Cunha R.L., Blanc F., Bonhomme F. \& Arnaud-Haond S., 2011. Evolutionary patterns in pearl oysters of the genus Pinctada (Bivalvia: Pteriidae). Marine Biotechnology, 13: 181-192. https://doi.org/10.1007/ s10126-010-9278-y
Di Geronimo I., 1971. Prima segnalazione sulle Coste italiane di Brachidontes variabilis Krauss. Bollettino delle sedute dell'Accademia Gioenia di Scienze Naturali di Catania, 10: 847-852.

Gardner J.P.A., Skibinski D.O.F. \& Bajdik C.D., 1993. Shell growth and viability differences between the marine mussels Mytilus edulis (L.), Mytilus galloprovincialis (Lmk.), and their hybrids from two sympatric populations in S.W. England. Biological Bulletin, 185: 405-416. https://doi.org/10.2307/1542 481

Gosling E., Doherty S. \& Howley N., 2008. Genetic characterization of hybrid mussel (Mytilus) populations on Irish coasts. Journal of the Marine Biological Association of the United Kingdom, 88: 341-346. https://doi.org/10.1017/S0025315408000957

Hynd J.S., 1955. A revision of the Australian pearl shells, genus Pinctada (Lamellibranchia). Australian Journal of Marine and Freshwater Research, 6: 98-137.

Koehn R.K., 1991. The genetics and taxonomy of species of the genus Mytilus. Aquaculture, species of the genus Mytilus. Aquaculture, 4: 125-145.

Manousis T. \& Galinou-Mitsoudi S., 2013. New and uncommon Bivalvia Mollusca of Thermaikos Gulf (NW Aegean Sea). Journal of Biological Research Thessaloniki, 20: 339-366. https://doi.org/10.1186/ 2241-5793-21-20

Monterosato di T.A., 1878. Enumerazione e sinonima delle conchiglie mediterranee. Giomale di Scienze Naturali ed Economiche di Palermo, 13: 61-115.

Oliverio M., Gerosa G. \& Cocco M., 1992. First record of Pinctada radiata (Bivalvia, Pteriidae) epibiont on the loggerhead sea turtle Caretta caretta (Chelonia, Cheloniidae). Bollettino Malacologico, 28: 149-152.

Paccagnella W., 1967. Conchiglie del Mar di Sicilia. Conchiglie, 3: 169-183.

Parenzan P., 1961. Contributo allo studio dei Molluschi marini di Lampedusa. Bollettino della Società dei Naturalisti in Napoli, 70: 21-29.

Ranson G., 1961. Les espèces d'huîtres perlières du genre Pinctada (biologie de quelques-unes d'entre elles). Institute Royal des Sciences Naturelles de Belgique, Mémoires, 2e série, $67: 1-95$.

Spada G., 1969. Ritrovamenti malacologici nel mare di Lampedusa. Conchiglie, 5: 12-19.

Tëmkin I., 2010. Molecular phylogeny of pearl oysters and their relatives (Mollusca, Bivalvia, Pterioidea). BMC Evolutionary Biology, 10: 342. https://doi.org/ 10.1186/1471-2148-10-342

Villari A. \& Scuderi D., 2017. Taxonomical notes on some poorly known mollusca species from the Strait of Messina (Italy). Biodiversity Journal, 8: 193204. 
Wada T.K. \& Temkin I., 2008. Taxonomy and phylogeny. In: Southgate P. \& Lucas J. (Eds.), The Pearl Oyster, Elsevier, p. 3776, The Netherlands.
Zibrowius H., 1992. Ongoing modifications on the Mediteranean marine fauna and flora by the establishment of exotic species. Mésogée, 51: 83-107. 